\title{
Prognostic impact of family history of cancer in Southern Chinese patients with esophageal squamous cell cancer
}

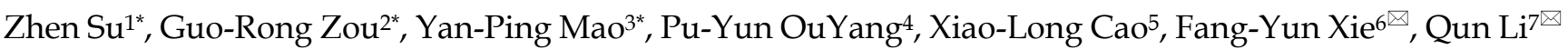 \\ 1. Panyu central hospital, Cancer Institute of Panyu, Guangzhou, China. \\ 2. Panyu central hospital, Cancer Institute of Panyu, Guangzhou, China. \\ 3. Department of Radiation Oncology, Sun Yat-sen University Cancer Center; State Key Laboratory of Oncology in South China; Collaborative Innovation \\ Center for Cancer Medicine, Guangzhou 510060, China. \\ 4. Department of Radiation Oncology, Sun Yat-sen University Cancer Center; State Key Laboratory of Oncology in South China; Collaborative Innovation \\ Center for Cancer Medicine, Guangzhou 510060, China. \\ 5. Panyu central hospital, Cancer Institute of Panyu, Guangzhou, China. \\ 6. Department of Radiation Oncology, Sun Yat-sen University Cancer Center; State Key Laboratory of Oncology in South China; Collaborative Innovation \\ Center for Cancer Medicine, Guangzhou 510060, China. \\ 7. Department of Radiation Oncology, Sun Yat-sen University Cancer Center; State Key Laboratory of Oncology in South China; Collaborative Innovation \\ Center for Cancer Medicine, Guangzhou 510060, China.
}

*These authors contributed equally to this work.

$\bowtie$ Corresponding authors: xiefy0758@sina.com and liqun0799@sina.com.

(C) Ivyspring International Publisher. This is an open access article distributed under the terms of the Creative Commons Attribution (CC BY-NC) license (https://creativecommons.org/licenses/by-nc/4.0/). See http://ivyspring.com/terms for full terms and conditions.

Received: 2018.04.05; Accepted: 2018.12.05; Published: 2019.02.07

\begin{abstract}
Background: First degree family history of cancer is associated with developing esophageal cancer and sparse data is about the impact on poor survival among established esophageal squamous cell cancer (ESCC) patients. In this study, we investigated the prognoses of patients with ESCC with a family history.

Methods: A total of 479 ESCC patients were retrospectively enrolled from a Southern Chinese institution. A positive family history was defined as having malignant cancer among parents and siblings. Kaplan-Meier plots and Cox proportional hazards regressions were applied for overall survival (OS) and progression-free survival (PFS).

Results: Among 479 patients, 119 (24.8\%) and 68 (14.2\%) reported a first-degree family history of cancer and digestive tract cancer, respectively. Compared with patients without a family history of cancer, the adjusted hazard ratios $(\mathrm{HR})$ among those with it were $1.40(95 \% \mathrm{Cl}, 1.08-1.82, \mathrm{p}=0.011)$ for death, $1.36(95 \% \mathrm{Cl}$, 1.05-1.76, $p=0.018$ ) for progression. Similar results were observed in those with a family history of digestive tract cancer $(H R=1.69,95 \% \mathrm{Cl}, 1.24-1.98, p=0.001$ for death and $H R=1.77,95 \% \mathrm{Cl}, 1.30-2.37, p<0.001$ for progression, respectively). Furthermore, there was a trend for increasing risk of overall mortality $(p=0.021$, $p=0.004$, respectively), and progression $(p=0.022, p=0.001$, respectively) with an increasing number of affected family members.

Conclusion: A first-degree family history of cancer, especially digestive tract cancer is associated with poor survival for established ESCC patients and plays an important role in prognosis. The patients with a family history of cancer might need a greater intensity of treatment and more frequent follow-up.
\end{abstract}

Key words: first degree family history of cancer; digestive tract cancer; esophageal squamous cell cancer; survival; prognosis.

\section{Introduction}

Esophageal cancer (EC) is the sixth most common cause of cancer death worldwide (1). It has two dominant histologic types: esophageal adenocarcinoma and esophageal squamous cell

carcinoma (ESCC). China is one of areas with the highest esophageal cancer incidence rates in the world (1). Around $50 \%$ of the worldwide cases occur in China. EC is the fourth most common malignancy in 
China $(2,3)$. Moreover, most cases of EC in China are squamous (1). With the development of multidisciplinary treatment (including surgery, chemotherapy and radiotherapy), the 5-year overall survival (OS) remains unsatisfactory. The 5-year OS rates for EC are $20 \%$ in the USA, $21 \%$ in China, $12 \%$ in Europe, and $<5 \%$ in the lower resource settings, suggesting that primary and secondary prevention are key to reducing mortality from this disease (4). Therefore, it is necessary to identify novel prognostic factors to recognize patients at high risk.

In the latest study of ESCC epidemiology, the risk factors have been summarized with consistent evidence. These factors included poverty, tobacco, alcoholic beverages, betel quid and so on (5). There is also substantial evidence for a inherited susceptibility in developing EC based on familial aggregation (6-8), segregation studies $(9,10)$ and candidate gene/genome-wide association studies (11-13). Importantly, family history of EC has consistently been associated with an increased risk of developing the disease $(6,8,14,15)$. A large scale study of case control design and reconstructed cohort design showed that a doubled risk of ESCC associated with a positive family history of esophageal cancer among first degree relatives (16). Family history comprises a mixture of habits and inherited genes, which are partly determined by genetic factors. Tylosis with ESCC has been linked to the autosomal dominant mutations in RHBDF2 gene and a high risk of ESCC is found in the ESCC patients with Tylosis, with a young age at onset and penetrance estimated to be as high as $90 \%(17,18)$. The latest literature published in Nature has identified some mutation or amplifications of ESCC, offering potential therapeutic targets (19). Mutations such as CDKN2A, BRCA2, were significantly different in patients with or without a family history $(20,21)$. However, there is no study concerning the question whether family history of ESCC is associated with survival among patients with established ESCC. The associations between a first degree family history of cancer and survivals have been studied in other cancers (22-25). Colon cancer (22) and gastric cancer (23) patients with a first degree family history showed a significant reduction in recurrence and death. Patients with a family history of breast cancer (24) or nasopharyngeal carcinoma (25) had better survivals as well. However, the association of first degree family history of cancer and survivals for patients with established ESCC has not been explored up to now. Therefore, we performed this study to evaluate the effect of a first degree family history of cancer on the clinicopathologic characteristics and survivals of patients with ESCC.

\section{Materials and methods}

\section{Patient characteristics.}

Between January 2007 and December 2013, 504 EC patients who were hospitalized at the Sun Yat-sen University Cancer Center receiving radiotherapy were potentially eligible for inclusion in this retrospective study. A total of 479 patients were eventually included who (1) were newly diagnosed, biopsy proven, non-metastasis ESCC, (2) without previous anticancer treatment, (3) had a complete pretreatment evaluation including patient history, physical examination, haematology and biochemistry profiles, computed tomography (CT) of neck, chest and upper abdomen, endoscopic ultrasound and (4) had a complete interview about family history and lifestyle behavior. Medical records were reviewed to extract data from our medical record system. The basic characteristics included age, gender, cigarette smoking status at diagnosis, alcohol drinking status at diagnosis and family history. All patients were restaged according to the sixth edition of the union for international cancer control (UICC) staging system. Those who had a missing information of basic characteristics or didn't complete radiotherapy were excluded.

\section{Treatment}

All patients were treated according to our institutional guidelines and national comprehensive cancer network guideline. All patients received radical radiation therapy (RT). Details of the radiation techniques have been described previously $(26,27)$. The chemotherapy regimens consisted of fluoropyrimidine- or taxane- based regimens (PF cisplatin with 5-fluoropyrimidine or TP cisplatin with taxoids ) every 3 weeks or weekly. The chemotherapy included induction chemotherapy (IC), concurrent chemoraidotherapy and adjuvant chemotherapy (AC).

\section{Family history assessment}

Family history of cancer was ascertained by self-reporting through an interview at the time of the index case diagnosis. We defined a family history of cancer as having at least one first-degree relative affected with cancer (16). The first degree relative included father, mother and siblings. The digestive tract cancer includes esophageal cancer, stomach cancer, liver cancer, pancreas cancer and colorectum cancer (16).

\section{Follow-up}

Patients were followed up at regular intervals after completing treatment, which were every 3 
months during the first 2 years, every 4-6 months during the first 3 to 5 years and annually thereafter. Regular assessment included physical examination, blood test, endoscopy, chest X-ray and ultrasound test. Computed tomography scan of the chest, abdomen, and cervical region was performed at least once a year. For those who could not afford regular follow up visits, a telephone follow-up was performed instead. The follow-up duration was calculated from the first day of treatment to either the day of death or the day of the last examination.

\section{Study endpoints}

Our study endpoints were overall survival (OS) and progression-free survival (PFS). OS was defined as the time from the completion of treatment to death resulting from any cause. PFS was defined as the time from completion of treatment to the first locoregional relapse, or distant metastasis, or death from any cause.

\section{Statistical methods}

Comparisons of demographic, clinical and pathologic variables were performed using $x^{2}$ statistic or Fisher's exact test for nominal variables as appropriate. The Kaplan-Meier method and log-rank test were used for analysis and comparison of survival curves. The multivariate Cox proportional hazards model was used to estimate hazard ratios $(\mathrm{HR})$ and 95\% confidence intervals (CI). Age $(<60$ years vs $\geq 60$ ), gender, smoking history (no vs yes), smoking history (no vs yes), T stage (T1/T2/T3/T4), $\mathrm{N}$ stage (N0 vs N1), M stage (M0 vs M1a), tumor location, histopathological grading (high vs middle vs low), treatment strategy and radiotherapy technology were included as variables. Two-sided P-values $<0.05$ were considered to be significant. All tests were conducted using IBM SPSS Statistics 22.0 (Chicago, USA).

\section{Results}

\section{Patient characteristics}

A total of 479 patients were enrolled as the target population. Of these, $119(24.8 \%)$ had a family history of cancer and $68(14.2 \%)$ had a family history of digestive tract cancer. The baseline demographic and clinical characteristics of patients were compared according to with or without a family history of cancer and digestive tract cancer (Table 1). There were no differences in the distributions of smoking history, drinking history, tumor location, histopathological grading, $\mathrm{T}$ stage, $\mathrm{M}$ stage, clinical stage, treatment strategy and radiotherapy technology. Significant differences were observed in age, gender and $\mathrm{N}$ stage.
The patients with a family history were more likely to be younger female and with N0 stage.

Table 1. Demographic and clinicopathologic characteristics of ESCC patients with or without an first degree family history of cancer (digestive tract cancer).

\begin{tabular}{|c|c|c|c|c|c|c|c|}
\hline & & \multicolumn{3}{|c|}{$\begin{array}{l}\text { First degree family } \\
\text { history of cancer }\end{array}$} & \multicolumn{3}{|c|}{$\begin{array}{l}\text { First degree family history } \\
\text { of digestive tract cancer }\end{array}$} \\
\hline & & $\begin{array}{l}\text { With } \\
\text { [cases } \\
(\%)]\end{array}$ & $\begin{array}{l}\text { Without } \\
\text { [cases } \\
(\%)]\end{array}$ & $\begin{array}{l}P \\
\text { value }\end{array}$ & $\begin{array}{l}\text { With } \\
\text { [cases } \\
(\%)]\end{array}$ & $\begin{array}{l}\text { Without } \\
\text { [cases }(\%)]\end{array}$ & $\begin{array}{l}P \\
\text { value }\end{array}$ \\
\hline \multicolumn{8}{|l|}{ Characteristics } \\
\hline All & 479 & $119(24.8)$ & $360(75.2)$ & & $68(14.2)$ & $411(85.8)$ & \\
\hline Age (year) & & & & 0.037 & & & 0.010 \\
\hline$<60$ & 234(48.9) & $68(57.1)$ & $166(46.1)$ & & $43(63.2)$ & 191(46.5) & \\
\hline$>=60$ & $245(51.1)$ & $51(42.9)$ & 194(53.9) & & $25(36.8)$ & $220(53.5)$ & \\
\hline Gender & & & & 0.004 & & & 0.002 \\
\hline male & $379(79.2)$ & $83(69.7)$ & $296(82.2)$ & & $44(64.7)$ & $335(81.5)$ & \\
\hline female & $100(20.8)$ & $36(30.3)$ & $64(17.8)$ & & $24(35.3)$ & $76(18.5)$ & \\
\hline Smoking & & & & 0.343 & & & 0.305 \\
\hline No & $164(34.2)$ & $45(37.8)$ & $119(33.1)$ & & $27(39.7)$ & 137(33.3) & \\
\hline Yes & $315(65.8)$ & $74(62.2)$ & $241(66.9)$ & & $41(60.3)$ & $274(66.7)$ & \\
\hline Drinking & & & & 0.658 & & & 0.964 \\
\hline No & $290(60.5)$ & $70(58.8)$ & $220(61.1)$ & & $41(60.3)$ & $249(60.6)$ & \\
\hline Yes & $189(39.5)$ & $49(41.2)$ & $140(38.9)$ & & 27(39.7) & 162(39.4) & \\
\hline $\begin{array}{l}\text { Histopathological } \\
\text { grading }\end{array}$ & & & & 0.711 & & & 0.547 \\
\hline High & $124(25.9)$ & $30(25.2)$ & $94(26.1)$ & & $17(25.0)$ & $107(26.0)$ & \\
\hline middle & $278(58.0)$ & $67(56.3)$ & $211(58.6)$ & & $37(54.4)$ & $241(58.6)$ & \\
\hline low & $77(16.1)$ & $22(18.5)$ & $55(15.3)$ & & $14(20.6)$ & $63(15.3)$ & \\
\hline T stage $^{+}$ & & & & 0.839 & & & 0.495 \\
\hline $\mathrm{T} 1$ & $9(1.9)$ & $2(1.7)$ & $7(1.9)$ & & $1(1.5)$ & $8(1.9)$ & \\
\hline $\mathrm{T} 2$ & $73(15.2)$ & $18(15.1)$ & $55(15.3)$ & & $9(13.2)$ & $64(15.6)$ & \\
\hline T3 & $262(54.7)$ & $69(58.0)$ & 193(53.6) & & $43(63.2)$ & $219(53.3)$ & \\
\hline $\mathrm{T} 4$ & $135(28.2)$ & $30(25.2)$ & 105(29.2) & & $15(22.1)$ & $120(29.2)$ & \\
\hline $\mathrm{N}_{\text {stage }}+$ & & & & 0.033 & & & 0.007 \\
\hline N0 & $58(12.1)$ & 21(17.6) & $37(10.3)$ & & $15(22.1)$ & $43(10.5)$ & \\
\hline N1 & $421(87.9)$ & $98(82.4)$ & $323(89.7)$ & & $53(77.9)$ & $368(89.5)$ & \\
\hline M stage $^{+}$ & & & & 0.169 & & & 0.789 \\
\hline M0 & $303(63.3)$ & $69(58.0)$ & $234(65.0)$ & & $44(64.7)$ & $259(63.0)$ & \\
\hline M1a & $176(36.7)$ & $50(42.0)$ & $126(35.0)$ & & $24(35.3)$ & $152(37.0)$ & \\
\hline Clinical stage $^{+}$ & & & & 0.209 & & & 0.301 \\
\hline I & $4(0.8)$ & $0(0)$ & $4(1.1)$ & & $0(0)$ & $4(1.0)$ & \\
\hline II & $72(15.0)$ & $21(17.6)$ & $51(14.2)$ & & $15(22.1)$ & $57(13.9)$ & \\
\hline III & $225(47.0)$ & $48(40.3)$ & $177(49.2)$ & & $29(42.6)$ & $196(47.7)$ & \\
\hline IV & $178(37.2)$ & $50(42.0)$ & $128(35.6)$ & & $24(35.3)$ & 154(37.5) & \\
\hline Tumor location & & & & 0.641 & & & 0.493 \\
\hline Cervical & $61(12.7)$ & $19(16.0)$ & $42(11.7)$ & & $11(16.2)$ & $50(12.2)$ & \\
\hline up & $139(29.0)$ & $35(29.4)$ & 104(28.9) & & 19(27.9) & $120(29.2)$ & \\
\hline middle & $239(49.9)$ & $56(47.1)$ & $183(50.8)$ & & $30(44.1)$ & $209(50.9)$ & \\
\hline down & $40(8.4)$ & $9(7.6)$ & $31(8.6)$ & & $8(11.8)$ & $32(7.8)$ & \\
\hline treatment & & & & 0.236 & & & 0.729 \\
\hline RT alone & $56(11.7)$ & $10(8.4)$ & $46(12.8)$ & & $7(10.3)$ & $49(11.9)$ & \\
\hline CCRT & $336(70.1)$ & $87(73.1)$ & $249(69.2)$ & & $49(72.1)$ & $287(69.8)$ & \\
\hline $\mathrm{RT}+\mathrm{AC}$ & $10(2.1)$ & $0(0)$ & $10(2.8)$ & & $0(0)$ & $10(2.4)$ & \\
\hline IC+CCRT & $42(8.8)$ & 12(10.1) & $30(8.3)$ & & $7(10.3)$ & $35(8.5)$ & \\
\hline $\mathrm{CCRT}+\mathrm{AC}$ & $35(7.3)$ & $10(8.4)$ & $25(6.9)$ & & $5(7.4)$ & $30(7.3)$ & \\
\hline RT technology & & & & 0.419 & & & 0.042 \\
\hline 2DCRT & $72(15.0)$ & $20(16.8)$ & $52(14.4)$ & & $17(25.0)$ & $55(13.4)$ & \\
\hline 3DCRT & $298(62.2)$ & $68(57.1)$ & $230(63.9)$ & & $36(52.9)$ & $262(63.7)$ & \\
\hline IMRT & $109(22.8)$ & $31(26.1)$ & $78(21.7)$ & & $15(22.1)$ & $94(22.9)$ & \\
\hline $\begin{array}{l}\text { Abbreviation: RT } \\
\text { adjuvant chemoth } \\
\text { conventional radi } \\
\text { therapy; IMRT: in } \\
+ \text { staged accordin } \\
\text { system. }\end{array}$ & $\begin{array}{l}\text { diation } t \\
\text { apy; IC: } \\
\text { on thera } \\
\text { sity moc } \\
\text { sixth U }\end{array}$ & $\begin{array}{l}\text { therapy; } \\
\text { inductio } \\
\text { py; } 3 \mathrm{DCI} \\
\text { dulated } \\
\text { JICC (uni }\end{array}$ & $\begin{array}{l}\text { RT: conc } \\
\text { hemother } \\
\text { diation the } \\
\text { for interr }\end{array}$ & $\begin{array}{l}\text { current } \\
\text { erapy; } 2 \\
\text { asional } \\
\text { erapy. } \\
\text { rnationa }\end{array}$ & $\begin{array}{l}\text { chemora } \\
\text { confor } 2 \\
\text { al cancer }\end{array}$ & $\begin{array}{l}\text { diotherapy } \\
\text { dimension } \\
\text { l radiation } \\
\text { control) st }\end{array}$ & \\
\hline
\end{tabular}

In total of the patients, $56(11.7 \%)$ patients received radiotherapy alone. $336(79.4 \%)$ patients received concurrent chemoradiotherapy (CCRT) in those patients receiving radiotherapy plus 
chemotherapy. 407 (85.0\%) patients received radiotherapy with the technology of three dimensional conformal radiotherapy (3DCRT)/ intensity modulated radiation therapy (IMRT). The other $72(15.0 \%)$ patients received two dimensional radiation therapy (2DRT).

\section{Effect of first degree family history of cancer on survival}

A first degree family history of cancer was associated with a significant high risk of death and progression (Figure 1). The 5 year OS rate was 29.8\% for patients with a first degree family history of cancer compared with $43.4 \%$ of those without such a profile $(p=0.033$, Figure 1A). Significant association remained unchanged after accounting for other important prognostic factors, including age group (categorical), gender, smoking status (no vs. yes), drinking status (no vs. yes), histopathological grading, tumor location, $\mathrm{T}$ stage, $\mathrm{N}$ stage, $\mathrm{M}$ stage (M0 vs M1a), treatment strategy and radiation technique. Compared with patients without a first degree family history of cancer, those with it had a multivariate HR of 1.40 (95\% CI=1.08-1.82, $p=0.011)$ for death (Table 2). Furthermore, the results for the risk of progression were quite similar to those for death. The 5-year PFS was $24.9 \%$ for patients with a first degree family history of cancer and $35.9 \%$ for those without $(p=0.033$, Figure 1B). In multivariate analyses, adjusted HR for PFS was 1.36 (95\% CI=1.05-1.76, $p=0.018$ ) (Table 2).

\section{Effect of first degree family history of digestive tract cancer on survival}

We also analyzed the association between the first degree family history of digestive tract cancer and survival in patients with ESCC. The 5-year OS rate was $24.7 \%$ for patients with a first degree family history of digestive tract cancer and $42.6 \%$ for those without $(p=0.008)$ (Figure 1C). The 5-year PFS rate was $19.7 \%$ for patients with a first degree family history of digestive tract cancer and $35.3 \%$ for those without ( $p=0.004$, Figure 1D). In multivariate analysis, the adjusted HRs of death and progression were 1.69 $(95 \% \mathrm{CI}=1.24-1.98, p=0.001)$ and $1.77(95 \% \mathrm{CI}=1.30-2.37$, $p<0.001$ ), respectively (Table 2).
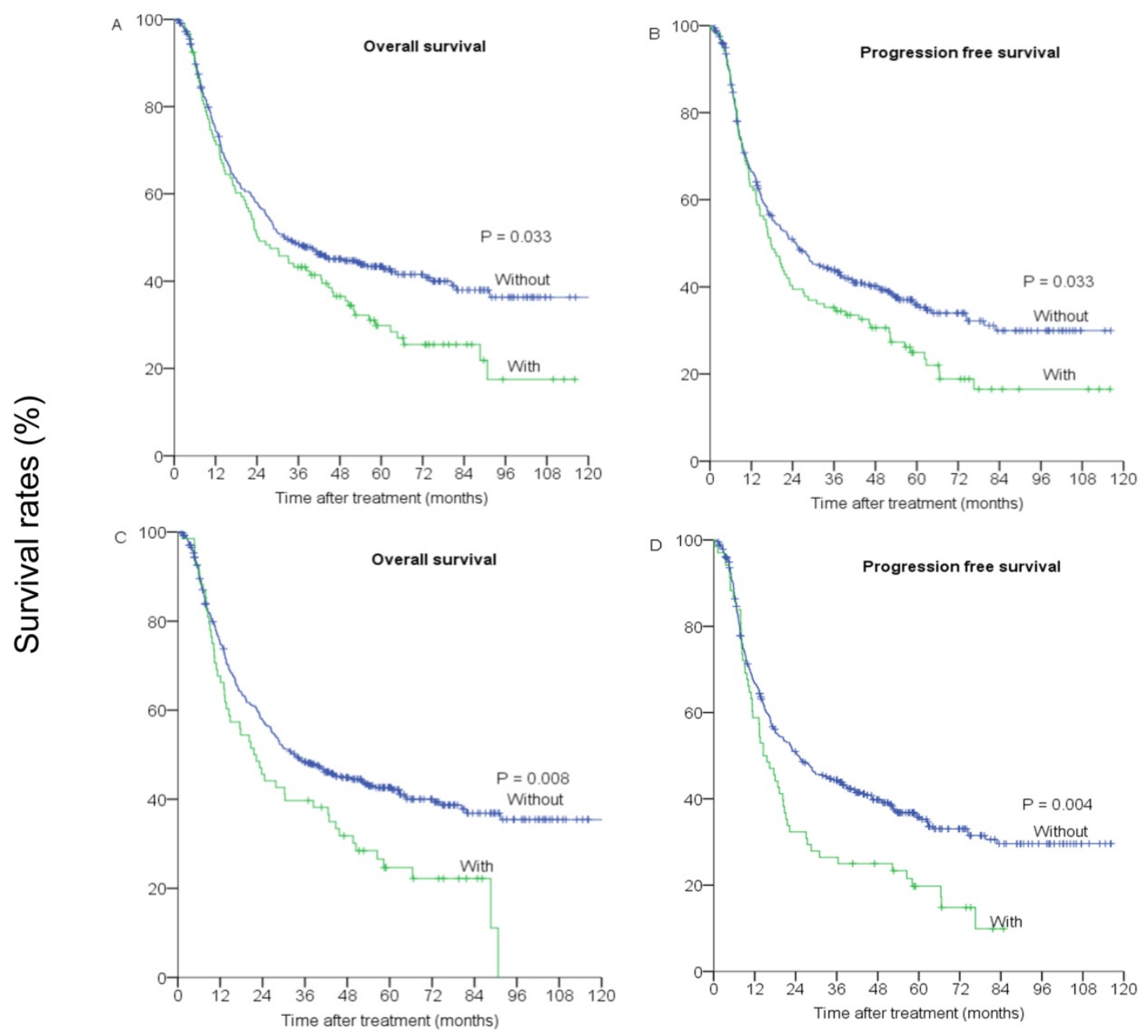

Figure 1. (A) and (C) overall survival, (B) and (D) progression-free survival of patients with and without a first degree family history of cancer (or digest tract cancer). 
Table 2. Multivariate analysis of prognostic factors for 479 esophageal squamous cell carcinoma patients

\begin{tabular}{|c|c|c|c|c|c|}
\hline & & OS & & PFS & \\
\hline & variable & HR $(95 \% \mathrm{CI})$ & $\begin{array}{l}\mathrm{P} \\
\text { value }\end{array}$ & HR (95\%CI) & $\begin{array}{l}\mathrm{P} \\
\text { value }\end{array}$ \\
\hline \multicolumn{6}{|l|}{$\begin{array}{l}\text { Analysis for a } \\
\text { family history of } \\
\text { cancer }\end{array}$} \\
\hline & age & $1.39(1.09-1.76)$ & 0.008 & $1.37(1.15-1.64)$ & $<0.001$ \\
\hline & $\mathrm{T}_{\text {stage }} \mathrm{e}^{+}$ & $1.43(1.20-1.70)$ & $<0.001$ & $1.49(1.22-1.81)$ & $<0.001$ \\
\hline & $\mathrm{M}$ stage $^{+}$ & $1.53(1.20-1.96)$ & 0.001 & $1.36(1.05-1.76)$ & 0.018 \\
\hline & $\begin{array}{l}\text { First degree } \\
\text { family history of } \\
\text { cancer }\end{array}$ & $1.40(1.08-1.82)$ & 0.011 & $1.37(1.15-1.64)$ & $<0.001$ \\
\hline \multicolumn{6}{|c|}{$\begin{array}{l}\text { Analysis for a } \\
\text { family history of } \\
\text { digest tract } \\
\text { cancer }\end{array}$} \\
\hline & age & $1.39(1.09-1.77)$ & 0.008 & $1.30(1.03-1.65)$ & 0.026 \\
\hline & $\mathrm{T}_{\text {stage }}{ }^{+}$ & $1.42(1.19-1.69)$ & $<0.001$ & $1.39(1.18-1.65)$ & $<0.001$ \\
\hline & M stage $^{+}$ & $1.55(1.21-1.98)$ & $<0.001$ & $1.56(1.24-1.98)$ & $<0.001$ \\
\hline & $\begin{array}{l}\text { First degree } \\
\text { family history of } \\
\text { digestive tract } \\
\text { cancer }\end{array}$ & $1.69(1.24-1.98)$ & 0.001 & $1.77(1.30-2.37)$ & $<0.001$ \\
\hline
\end{tabular}

Abbreviation: OS: overall survival; PFS: progression-free survival.

+ staged according to sixth UICC (union for international cancer control)stage system.

a adjusted by the variables: age ( $<60$ years vs $\geq 60$ ), gender, smoking history (no vs yes), smoking history (no vs yes), T stage, $N$ stage, M stage (M0 vs M1a), tumor location, Histopathological grading, treatment, radiotherapy technology and first degree family history of cancer (or first degree family history of digest tract cancer).

\section{Strata analysis for the associations between a positive first-degree family history and OS and PFS.}

In addition, we assessed the association between a positive first degree family history of cancer (or digestive tract cancer) and OS and PFS across strata of other potential predictors of patients survivals (Table 3). The effects of first degree family history of cancer (or digestive tract cancer) on the risk of death and progress was not significantly modified by gender, smoking and drinking status. Furthermore, in the patients with age $<60$ years, a first degree family history of cancer had significant association with OS and PFS (adjusted HR=1.49, 95\%CI=1.03-2.18, $p=0.037$ and adjusted $\mathrm{HR}=1.46,95 \% \mathrm{CI}=1.02-2.09, p=0.040$, respectively). A first degree family history of digestive tract cancer among patients with aged $<60$ years had the similar results (adjusted $H R=1.71,95 \%$ $\mathrm{CI}=1.13-2.57, p=0.011$ for death and adjusted $\mathrm{HR}=1.79$, 95\% CI=1.21-2.66, $p=0.004$ for progression, respectively). The significant impact of first degree family history of cancer on the risk of death and progression remained significant in those patients received radiotherapy combined with chemotherapy (adjusted HR of death=1.44, 95\%CI=1.09-1.90, $p=0.011$; adjusted HR of progression $=1.45,95 \%$ $\mathrm{CI}=1.11-1.90, p=0.006$ ) and those patients with 3DCRT/IMRT technology (adjusted HR of death $=1.53,95 \% \mathrm{CI}=1.14-2.06, p=0.005 ;$ adjusted $\mathrm{HR}$ of progression $=1.39,95 \% \mathrm{CI}=1.05-1.84, p=0.023)$. The impact of first degree family history of digestive tract cancer on the risk of death and progression remained significant in those patients received radiotherapy combined with chemotherapy (adjusted HR of death $=1.73,95 \% \mathrm{CI}=1.23-2.42, p=0.001$; adjusted HR of progression=1.83, $95 \% \mathrm{CI}=1.33-2.53, \quad p<0.001)$ and those patients with 3DCRT/IMRT technology (adjusted HR of death=1.74, 95\% CI=1.20-2.53, $p=0.004$; adjusted HR of progression $=1.69$, 95\% CI=1.18-2.41, $p=0.004$ ).

\section{Multivariate analysis for OS and PFS based on the relative numbers and types in first-degree relatives.}

We also performed the multivariate analysis for the OS and PFS based on the numbers and the type of the first degree family history of cancer and digest tract cancer, respectively (Table 3). Compared with patients without a first-degree family history of cancer, those with one affected relative had a multivariate HR of 1.39 (95\% CI=1.06-1.84, $p=0.018$ ) for death, 1.38 (95\% CI=1.06-1.81, $p=0.017)$ for progression. For patients with two or two more affected first-degree relatives, we observed a multivariate $\mathrm{HR}$ of 1.67 (95\% CI=0.95-2.94, $p=0.075$ ) for death, $1.58 \quad(95 \% \mathrm{CI}=0.93-2.68, p=0.087)$ for progression. Compared with patients without a first-degree family history of digestive tract cancer, those with one affected relative had a multivariate HR of $1.70(95 \% \mathrm{CI}=1.21-2.38, p=0.002)$ for death, 1.81 (95\% CI=1.31-2.51, $p<0.001)$ for progression. For patients with two or two more affected first-degree relatives, we observed a multivariate $\mathrm{HR}$ of 1.66 (95\% CI $=0.86-3.24, \quad p=0.134) \quad$ for death, 1.59 $(95 \% \mathrm{CI}=0.84-2.98, p=0.152)$ for progression. There was a trend for increasing risk of overall mortality ( $p=0.021$ and $p=0.004$, respectively), and progression ( $p=0.022$ and $p=0.001$, respectively) with an increasing number of affected family members.

We also analyzed the association between relative types and survivals. Compared to those without a family history, patients with parents having a family history of cancer had a significant adjusted HR of $1.44(95 \% \mathrm{CI}=1.06-1.97, p=0.022)$ for death, 1.40 (95\% CI=1.03-1.89, $p=0.030$ ) for progression. Similar associations were observed among the patients with parents having a family history of digestive cancer ( $\mathrm{HR}$ of death=1.84, 95\% CI=1.33-2.54, $p<0.001$; HR of progression $=1.91, \quad 95 \% \mathrm{CI}=1.39-2.62, \quad p<0.001$, respectively). However, compared to those without a family history, patients with siblings having a family history, no significant results were observed except an adjusted HR of $1.44(95 \% \mathrm{CI}=1.01-2.06, \mathrm{p}=0.047)$ for progression. 
Table 3. Strata analysis of OS and PFS by patients' characteristics in terms of with or without first degree family history of cancer and digestive tract cancer.

\begin{tabular}{|c|c|c|c|c|c|c|c|c|}
\hline & \multicolumn{4}{|c|}{ First degree family history of cancer } & \multicolumn{4}{|c|}{ First degree family history of digestive tract cancer } \\
\hline & OS & & PFS & & OS & & PFS & \\
\hline factor & $\mathrm{HR}(95 \% \mathrm{CI})$ & $P$ value & $\mathrm{HR}(95 \% \mathrm{CI})$ & $P$ value & $\mathrm{HR}(95 \% \mathrm{CI})$ & $P$ value & $\mathrm{HR}(95 \% \mathrm{CI})$ & $P$ value \\
\hline \multicolumn{9}{|l|}{ age } \\
\hline$<60$ & $1.49(1.03-2.18)$ & 0.037 & $1.46(1.02-2.09)$ & 0.040 & $1.71(1.13-2.57)$ & 0.011 & $1.79(1.21-2.66)$ & 0.004 \\
\hline$>60$ & $1.35(0.92-1.98)$ & 0.128 & $1.34(0.92-1.93)$ & 0.123 & $1.56(0.94-2.60)$ & 0.086 & $1.64(1.00-2.69)$ & 0.051 \\
\hline \multicolumn{9}{|l|}{ gender } \\
\hline male & $1.31(0.98-1.76)$ & 0.067 & 1.32(0.99-1.75) & 0.056 & $1.53(1.07-2.20)$ & 0.021 & $1.61-1.13-2.31)$ & 0.009 \\
\hline female & $2.02(1.09-3.73)$ & 0.025 & $1.87(1.06-3.29)$ & 0.031 & $2.00(1.02-3.90)$ & 0.043 & $1.96(1.08-3.56)$ & 0.028 \\
\hline \multicolumn{9}{|l|}{ smoking } \\
\hline no & $1.70(1.05-2.74)$ & 0.031 & $1.54(0.99-2.40)$ & 0.056 & $2.05(1.17-3.60)$ & 0.012 & $1.99(1.19-3.34)$ & 0.009 \\
\hline yes & $1.34(0.98-1.83)$ & 0.071 & $1.36(0.99-1.86)$ & 0.052 & $1.48(1.01-2.17)$ & 0.044 & $1.54(1.05-2.34)$ & 0.026 \\
\hline \multicolumn{9}{|c|}{ Histopathological grading } \\
\hline high & $1.86(1.05-3.29)$ & 0.034 & $1.82(1.06-3.12)$ & 0.030 & $1.35(0.62-2.92)$ & 0.444 & $1.34(0.64-2.77)$ & 0.438 \\
\hline middle & $1.40(1.00-1.97)$ & 0.051 & $1.35(0.97-1.87)$ & 0.073 & $1.59(1.06-2.39)$ & 0.025 & $1.60(1.07-2.37)$ & 0.023 \\
\hline low & $0.84(0.40-1.78)$ & 0.658 & $0.86(0.42-1.74)$ & 0.669 & $3.32(1.29-8.52)$ & 0.013 & $2.89(1.29-6.50)$ & 0.010 \\
\hline \multicolumn{9}{|l|}{ Tumor location } \\
\hline Cervical+up & $1.46(0.97-2.22)$ & 0.071 & $1.28(0.86-1.90)$ & 0.226 & $1.48(0.89-2.44)$ & 0.126 & $1.44(0.89-2.33)$ & 0.140 \\
\hline Middle+low & $1.39(0.99-1.95)$ & 0.059 & $1.43(1.03-1.99)$ & 0.032 & $1.79(1.18-2.72)$ & 0.006 & $1.94(1.29-2.92)$ & 0.002 \\
\hline \multicolumn{9}{|l|}{ Clinical stage $^{+}$} \\
\hline $\mathrm{I}+\mathrm{II}$ & $1.79(0.83-3.86)$ & 0.134 & $1.45(0.70-2.98)$ & 0.316 & $1.83(0.78-4.30)$ & 0.165 & $1.43(0.63-3.22)$ & 0.396 \\
\hline III & $1.29(0.86-1.94)$ & 0.224 & $1.42(0.96-2.09)$ & 0.077 & $1.77(1.04-2.99)$ & 0.035 & $1.90(1.15-3.14)$ & 0.012 \\
\hline IVa & $1.55(1.03-2.34)$ & 0.036 & $1.46(0.98-2.18)$ & 0.061 & $1.63(1.00-2.66)$ & 0.050 & $1.74(1.08-2.83)$ & 0.024 \\
\hline \multicolumn{9}{|l|}{ Treatment } \\
\hline RT alone & $1.38(0.46-4.19)$ & 0.566 & $1.07(0.38-3.02)$ & 0.891 & $1.27(0.36-4.41)$ & 0.711 & $1.83(0.55-6.12)$ & 0.326 \\
\hline $\mathrm{RT}+\mathrm{CT}$ & $1.44(1.09-1.90)$ & 0.011 & $1.45(1.11-1.90)$ & 0.006 & $1.73(1.23-2.42)$ & 0.001 & $1.83(1.33-2.53)$ & $<0.001$ \\
\hline \multicolumn{9}{|l|}{ RT technology } \\
\hline 2DCRT & $0.69(0.36-1.33)$ & 0.262 & $1.07(0.55-2.09)$ & 0.831 & $0.75(0.37-1.50)$ & 0.413 & $1.09(0.53-2.25)$ & 0.807 \\
\hline 3DCRT+IMRT & $1.53(1.14-2.06)$ & 0.005 & $1.39(1.05-1.84)$ & 0.023 & $1.74(1.20-2.53)$ & 0.004 & $1.69(1.18-2.41)$ & 0.004 \\
\hline \multicolumn{9}{|c|}{ Number of first-degree relatives } \\
\hline 0 & reference & & & & reference & & reference & reference \\
\hline 1 & $1.39(1.06-1.84)$ & 0.018 & $1.38(1.06-1.81)$ & 0.017 & $1.70(1.21-2.38)$ & 0.002 & $1.81(1.31-2.51)$ & $<0.001$ \\
\hline$\geq 2$ & $1.67(0.95-2.94)$ & 0.075 & $1.58(0.93-2.68)$ & 0.087 & $1.66(0.86-3.24)$ & 0.134 & $1.59(0.84-2.98)$ & 0.152 \\
\hline$P$ for trend & & 0.021 & & 0.022 & & 0.004 & & 0.001 \\
\hline \multicolumn{9}{|c|}{ Relative type in first-degree relatives } \\
\hline 0 & reference & & & & reference & & reference & \\
\hline parents & $1.44(1.06-1.97)$ & 0.022 & $1.40(1.03-1.89)$ & 0.030 & $1.84(1.33-2.54)$ & $<0.001$ & $1.91(1.39-2.62)$ & $<0.001$ \\
\hline siblings & $1.42(0.97-2.07)$ & 0.071 & $1.44(1.01-2.06)$ & 0.047 & $0.95(0.40-2.34)$ & 0.918 & $1.15(0.54-2.48)$ & 0.715 \\
\hline$P$ for trend & & 0.026 & & 0.025 & & 0.001 & & $<0.001$ \\
\hline
\end{tabular}

\section{Discussion}

Our study included 479 ESCC patients, among which $119(24.8 \%)$ had a family history of cancer in first degree relatives included parents and siblings and $68(14.2 \%)$ had a family history of digestive tract cancer. The involved patients received radiotherapy and chemotherapy and were from Southern China. The object patients in previous studies from China were from Northern China $(7,9,10,16)$, which the eating habits and the environment were different from Southern China. Our study focused on the impact of patients having a family history of cancer on survival and demonstrated that a first degree family history of cancer (especially digestive tract cancer) is an independent, prognostic factor for poor survival in patients with established ESSC after adjusting for known prognostic factors. Interesting, we found that the HR of OS was close to the HR of PFS. The poor survival after progression of ESCC might be the main reason (28). Our findings were quite different from previous studies in colorectal cancer (29), colon cancer (22), gastric cancer, breast cancer (24) and nasopharyngeal carcinoma (25), which a family history of cancer was associated with a significant reduction in the risk of death. Furthermore, no familial link was found in two case-control study from United States and Swedish, respectively, nether for ESCC or for esophageal adenocarcinoma $(15,30)$. Our results were comparable to the two studies which the object patients receiving surgery were from West China (31), and Northern China (32).

The inconsistency in results might arise from different frequency of ESCC susceptibility alleles (genetic susceptibility) and variation in attributable environmental or lifestyle risk factors, or a combination of both. It is not clear why a family history of cancer affects patients' survival, but variability in adherence to surveillance monitoring, health-related behavior, or genetic differences may explain our observations. Individuals with a family history of the disease may be more sensitive to the 
signal of ESCC and more likely to undergo the early diagnosis and treatment, which may make bias. In our study, most patients were local advanced stage. We believe that the bias from the early diagnosis and treatment effect could be minimized in our study by adjustment for tumor stage. Further study on early stage ESCC is needed to clarify this point.

Health-related behavior may contribute to this survival difference. Patients with a family history of cancer were more likely to have a similar behavior. The risk of developing EC was slightly higher for siblings, compared with parents, indicating that recessive or X-linked susceptibility genes might be involved in the occurrence of ESSC, and the siblings share more lifestyle risk factors. No significant effects of family history were observed in second- or third-degree relatives (23-25). The second- or third-degree relatives are less likely to share similar susceptibility genes and lifestyle risk factors. Lifestyle risk factors such as tobacco smoking or alcohol intake was associated with poor prognosis in ESCC patients. Exome and whole-genome studies also reveal the importance contribution of genetic susceptibility to the occurrence of ESCC (33-35). A study proved that for a disease with notable familial aggregation, environmental factors alone cannot account for such a strong aggregation (36). In addition, one study showed that a younger age of ESCC development results from the interaction of environmental and genetic risk factors (37). So we inferred that environmental and genetic risk factors might cooperate hand in hand affecting the survivals. In our study, we also have collected the exposure information of the ESCC patients. We tried our best to distinguish the effects of genetic susceptibility from the environment factors. In the multivariate analysis including smoking status and drinking status, a first degree family history of cancer (especially digestive tract cancer) remained significantly associated with poor survival. In the strata analysis by smoking status and drinking status, we got the similar results, too. The HR was higher in patients without a smoking history than those with. Therefore, we inferred that a family history and smoking history cooperated and a family history might play a more important role. Finally, we also analyzed the associations between the survivals and the numbers and the relative type of patients with a family history. The previous study of the impact on survival didn't take the exposure into consideration, though similar results were obtained (7). Further researches into genetic differences and environment factors were needed to fully elucidate the potential mechanisms.

As in the previous studies demonstrated a strong tendency toward familial aggregation, genetic susceptibility may play a role in the etiology of esophageal cancer and affect the survivals. Loss of heterozygosity (LOH) is more common in patients with a family history of upper gastrointestinal cancer than in those without such history (38). Two markers (D6S1027 on 6q and D9S910 on 9q) had significantly more $\mathrm{LOH}$ in patients with metastasis, and one marker (D4S2361 on 4p) showed significantly higher $\mathrm{LOH}$ in patients with a lower pathological tumor grade. These might explain why the patients with a family history have a poorer survival. $\mathrm{LOH}$ is significantly associated with poorer prognosis of glioma patients and colorectal cancers $(39,40)$. In our study, we found that the HR of a family history of digestive tract cancer was higher than those with a family history of cancer (not only digestive tract cancer but also other types of cancer). In the study by Chen, the HR of excess ESCC risks of a family history of digestive tract cancer was 1.55 (95\% CI=1.23-1.96), higher than those with a family history of any cancer (adjusted HR=1.43, 95\% CI=1.13-1.81) (16). We inferred that the patients with a family history of digest tract cancer were more likely to have the genetic susceptibility than those with a family history of cancer. Further studies are needed to determine the influence of this genetic difference on the observed survival differences according to the family history.

The following limitations of this study deserve comment. First, the sample may be small. However, in the study reported by Tian, the cumulative risk of esophageal cancer to age 75 was $12.2 \%$ in the first-degree relatives of cases and $7.0 \%$ in those of controls (hazard ratio $=1.91,95 \%$ CI: $1.54-2.37$ ). The incidence of family history among esophageal cancer patients was not high. Our involved patients were strict to those who treated with chemoradiotherapy in our single institution of Southern China. We did not involve patients who received surgery or treated in other different institutions. Our results were comparable to the previous studies that patients treated with surgery and were from Northern China or West China (31, 32). Second, like other retrospective studies in $\mathrm{EC}$, the treatment regimens were not totally consistent with the latest NCCN guidelines and the stage was based on the sixth UICC stage system, not the latest seventh UICC stage system. The latest seventh UICC stage system of ESCC is more widely applied to those patients undergoing surgery. During the period when patients were treated, many patients were encouraged to participate in randomized trials, which also resulted in heterogeneous strategies. But we performed the multivariate analysis and strata analysis accounting for RT technology and chemotherapy regiments. Third, we have neglected and missed the data of 
education and incomes of patients. Low education and low income increase the risk of each subtype of esophageal and gastric cancer (41, 42). Educational attainment and income also might play an important role in treatment choice for patients, which have an impact on survival. Higher household income was associated with a 33\%-38\% decrease in risk for death (43). In our study, we selected those patients completing radiotherapy and chemotherapy to reduce the bias. Fourth, in our study, we relied on self-reported family history and might possibly misclassify family history status and we could not collect the information on the age at which the first degree relative was diagnosed with cancer, as the effect of family history might be different according to it. In addition, it is not clear why a first degree family history of cancer affects survival of patients. Our study showed young patients accounted for a much higher proportion among the patients with a family history of cancer (or digestive tract cancer), which strongly supports an assumption of surveillance monitoring for individuals with a family history. Patients with a family history had a lower percentage N1 stage than those with a family history $(p=0.033$, $p=0.007$, respectively). Furthermore, the patients with a family history had a poorer survival than those without a family history, which might indicated that the biological behaviors were more aggressive than those without a family history. Underlying molecular and pathogenic differences might play an intrinsic role in the effect of family history. Further basic researches into genetic differences were needed to fully elucidate the potential mechanisms.

\section{Conclusion}

In conclusion, our study showed poorer survival for patients who had a first degree family history of cancer (especially digestive tract cancer) than for patients without this profile. Further studies are needed to explore the biological, genetic or behavioral differences in ESSC according to the presence of family history.

\section{Abbreviations}

EC: esophageal cancer; SCC: squamous cell carcinoma; ESCC: esophageal squamous cell carcinoma; CT: computed tomography; UICC: union for international cancer control; RT: radiation therapy; NCCN: national comprehensive cancer network; IC: induction chemotherapy; AC: adjuvant chemotherapy; OS: overall survival; PFS: progression-free survival; HR: hazard ratios; CI: confidence intervals; CCRT: concurrent chemoradiotherapy; 3DCRT: three-dimensional conformal radiotherapy; IMRT: intensity modulated radiotherapy; 2DRT: two-dimensional radiotherapy.

\section{Acknowledgments}

We appreciated all individuals, particularly the people of Clinical Research Ethics Committee of Sun Yat-Sen University Cancer Center, including doctors, nurses, coordinators, and the Data Management team who generously spared their time for the accomplishment and fulfillment of this project.

\section{Ethics approval and consent to participate}

This retrospective study was approved by the Clinical Research Ethics Committee of Sun Yat-Sen University Cancer Canter. Patient records were anonymized and de-identified prior to analysis.

\section{Availability of data and material}

Raw data may be available on request from the corresponding author.

\section{Authors' contributions}

SZ, ZGR, LQ and XFY designed the study; SZ, MYP, and OYPY collected the data; SZ, ZGR, MYP and OYPY analyzed the results; SZ and MYP drafted the manuscript; SZ, ZGR, CXL and XFY revised the manuscript. LQ and XFY are responsible for the overall content. All authors have read and approved the final manuscript.

\section{Competing Interests}

The authors have declared that no competing interest exists.

\section{References}

1. Ajani JA, D'Amico TA, Almhanna K, et al. Esophageal and esophagogastric junction cancers, version 1.2015. J Natl Compr Canc Netw 2015; 13:194-227.

2. Chen $\mathrm{W}$, Zheng $\mathrm{R}$, Zeng $\mathrm{H}$, Zhang $\mathrm{S}$. The incidence and mortality of major cancers in China, 2012. Chin J Cancer 2016; 35:73.

3. Chen W, Zheng R, Baade PD, et al. Cancer statistics in China, 2015. CA Cancer J Clin 2016; 66:115-132.

4. Murphy G, McCormack V, Abedi-Ardekani B, et al. International cancer seminars: a focus on esophageal squamous cell carcinoma. Ann Oncol 2017; 28:2086-2093.

5. Abnet CC, Arnold M, Wei WQ. Epidemiology of Esophageal Squamous Cell Carcinoma. Gastroenterology 2018; 154: 360-73

6. Akbari MR, Malekzadeh R, Nasrollahzadeh D, et al. Familial risks of esophageal cancer among the Turkmen population of the Caspian littoral of Iran. Int J Cancer 2006; 119:1047-1051.

7. Gao Y, Hu N, Han X, et al. Family history of cancer and risk for esophageal and gastric cancer in Shanxi, China. Bmc Cancer 2009; 9:269.

8. Garavello W, Negri E, Talamini R, et al. Family history of cancer, its combination with smoking and drinking, and risk of squamous cell carcinoma of the esophagus. Cancer Epidemiol Biomarkers Prev 2005; 14:1390-1393.

9. Carter $\mathrm{CL}, \mathrm{Hu} \mathrm{N}, \mathrm{Wu}$ M, Lin PZ, Murigande C, Bonney GE. Segregation analysis of esophageal cancer in 221 high-risk Chinese families. J Natl Cancer Inst 1992; 84:771-776.

10. Zhang W, Bailey-Wilson JE, Li W, et al. Segregation analysis of esophageal cancer in a moderately high-incidence area of northern China. Am J Hum Genet 2000; 67:110-119.

11. Zhang $X$, Miao $X$, Tan $W$, et al. Identification of functional genetic variants in cyclooxygenase-2 and their association with risk of esophageal cancer. Gastroenterology 2005; 129:565-576.

12. Larsson SC, Giovannucci E, Wolk A. Folate intake, MTHFR polymorphisms, and risk of esophageal, gastric, and pancreatic cancer: a meta-analysis. Gastroenterology 2006; 131:1271-1283. 
13. Yang SJ, Wang HY, Li XQ, et al. Genetic polymorphisms of ADH2 and ALDH2 association with esophageal cancer risk in southwest China. World J Gastroenterol 2007; 13:5760-5764.

14. Morita M, Saeki H, Mori M, Kuwano H, Sugimachi K. Risk factors for esophageal cancer and the multiple occurrence of carcinoma in the upper aerodigestive tract. Surgery 2002; 131:S1-S6.

15. Dhillon PK, Farrow DC, Vaughan TL, et al. Family history of cancer and risk of esophageal and gastric cancers in the United States. Int J Cancer 2001; 93:148-152.

16. Chen $\mathrm{T}$, Cheng $\mathrm{H}$, Chen $\mathrm{X}$, et al. Family history of esophageal cancer increases the risk of esophageal squamous cell carcinoma. Sci Rep-Uk 2015; 5:16038.

17. Blaydon DC, Etheridge SL, Risk JM, et al. RHBDF2 mutations are associated with tylosis, a familial esophageal cancer syndrome. Am J Hum Genet 2012; 90:340-346.

18. Marger RS, Marger D. Carcinoma of the esophagus and tylosis. A lethal genetic combination. Cancer-Am Cancer Soc 1993; 72:17-19.

19. Cancer Genome Atlas Research Network, et al. Integrated genomic characterization of oesophageal carcinoma. Nature 2017; 541:169-175.

20. $\mathrm{Hu} \mathrm{N}$, Wang $\mathrm{C}, \mathrm{Su} \mathrm{H}$, et al. High frequency of CDKN2A alterations in esophageal squamous cell carcinoma from a high-risk Chinese population. Genes Chromosomes Cancer 2004; 39:205-216.

21. Hu N, Wang $\mathrm{C}, \mathrm{Han} X Y$, et al. Evaluation of BRCA2 in the genetic susceptibility of familial esophageal cancer. Oncogene 2004; 23:852-858.

22. Chan JA, Meyerhardt JA, Niedzwiecki D, et al. Association of family history with cancer recurrence and survival among patients with stage III colon cancer. JAMA 2008; 299:2515-2523.

23. Han MA, Oh MG, Choi IJ, et al. Association of family history with cancer recurrence and survival in patients with gastric cancer. J Clin Oncol 2012; 30:701-708.

24. Malone KE, Daling JR, Doody DR, et al. Family history of breast cancer in relation to tumor characteristics and mortality in a population-based study of young women with invasive breast cancer. Cancer Epidemiol Biomarkers Prev $2011 ; 20: 2560-2571$

25. OuYang P, Su Z, Mao Y, Liang X, Liu Q, Xie F. Prognostic impact of family history in southern Chinese patients with undifferentiated nasopharyngeal carcinoma. Brit J Cancer 2013; 109:788-794.

26. Zhang $\mathrm{P}, \mathrm{Xi} \mathrm{M}, \mathrm{Li} \mathrm{QQ}$, et al. Concurrent cisplatin and 5-fluorouracil versus concurrent cisplatin and docetaxel with radiotherapy for esophageal squamous cell carcinoma: a propensity score-matched analysis. Oncotarget 2016; 7:44686-44694.

27. Liu $\mathrm{H}, \mathrm{Lu} \mathrm{L}$, Zhu $\mathrm{Q}$, et al. Cervical nodal metastases of unresectable thoracic esophageal squamous cell carcinoma: characteristics of long-term survivors after concurrent chemoradiotherapy. Radiother Oncol 2011; 99:181-186.

28. Wu SG, Zhang WW, He ZY, Sun JY, Chen YX, Guo L. Sites of metastasis and overall survival in esophageal cancer: a population-based study. Cancer Manag Res 2017; 9:781-788.

29. Morris EJ, Penegar S, Whitehouse LE, et al. A retrospective observational study of the relationship between family history and survival from colorectal cancer. Br J Cancer 2013; 108:1502-1507.

30. Lagergren J, Ye W, Lindgren A, Nyren O. Heredity and risk of cancer of the esophagus and gastric cardia. Cancer Epidemiol Biomarkers Prev 2000; 9:757-760.

31. Yuequan J, Shifeng C, Bing Z. Prognostic factors and family history for survival of esophageal squamous cell carcinoma patients after surgery. Ann Thorac Surg 2010; 90:908-913.

32. Wen D, Wang S, Zhang L, Zhang J, Wei L, Zhao X. Differences of onset age and survival rates in esophageal squamous cell carcinoma cases with and without family history of upper gastrointestinal cancer from a high-incidence area in North China. Fam Cancer 2006; 5:343-352.

33. Chen J, Kwong DL, Cao T, et al. Esophageal squamous cell carcinoma (ESCC): advance in genomics and molecular genetics. Dis Esophagus 2015; 28:84-89.

34. Song Y, Li L, Ou Y, et al. Identification of genomic alterations in oesophageal squamous cell cancer. Nature 2014; 509:91-95.

35. Dulak AM, Stojanov P, Peng S, et al. Exome and whole-genome sequencing of esophageal adenocarcinoma identifies recurrent driver events and mutational complexity. Nat Genet 2013; 45:478-486.

36. Khoury MJ, Beaty TH, Liang KY. Can familial aggregation of disease be explained by familial aggregation of environmental risk factors? Am J Epidemiol 1988; 127:674-683.

37. Jia N, Wen $X$, Zhang N, et al. Younger age of onset and multiple primary lesions associated with esophageal squamous cell carcinoma cases with a positive family history of the cancer suggests genetic predisposition. Chin Med J (Engl) 2014; 127:2779-2783.

38. $\mathrm{Hu} \mathrm{N}$, Roth MJ, Emmert-Buck MR, et al. Allelic loss in esophageal squamous cell carcinoma patients with and without family history of upper gastrointestinal tract cancer. Clin Cancer Res 1999; 5:3476-3482.

39. Huang T, Li S, Yang Z, Liu J, Han Y. Loss of Heterozygosity of 9p Is Associated with Poorer Survival in Patients with Gliomas. Mol Neurobiol 2016; 53:6407-6412.

40. Jia X, Shanmugam C, Paluri RK, et al. Prognostic value of loss of heterozygosity and sub-cellular localization of SMAD4 varies with tumor stage in colorectal cancer. Oncotarget 2017; 8:20198-20212.

41. Lagergren J, Andersson G, Talback M, et al. Marital status, education, and income in relation to the risk of esophageal and gastric cancer by histological type and site. Cancer-Am Cancer Soc 2016; 122:207-212.
42. Gammon MD, Schoenberg JB, Ahsan $\mathrm{H}$, et al. Tobacco, alcohol, and socioeconomic status and adenocarcinomas of the esophagus and gastric cardia. J Natl Cancer Inst 1997; 89:1277-1284.

43. Trivers KF, De Roos AJ, Gammon MD, et al. Demographic and lifestyle predictors of survival in patients with esophageal or gastric cancers. Clin Gastroenterol Hepatol 2005; 3:225-230. 